\title{
Ilizarov Fixator in Treatment of Intertrochanteric Fracture Femur in Geriatric High Risk Patients
}

\author{
Ahmed Ibrahim Zayda*, El-Sayed Morsi Zaki and Sameh Marei \\ Orthopedic Surgery Department, Faculty of Medicine-Menoufia University, Egypt
}

Received: January 17, 2018; Published: January 24, 2018

*Corresponding author: Ahmed Ibrahim Zayda, Orthopedic Surgery Department, Faculty of Medicine-Menoufia University, Maxim Street, Shebin Al-Kom, Menoufia, Egypt, Tel: 01006993055; Email: dr.ahmedzayda2018@gmail.com

Abstract

Objective: To assess the effectiveness of fixation of intertrochanteric fracture in geriatric high risk patients by Ilizarov fixator.

Background: Internal fixation of intertrochanteric fractures in patients with anaesthetic or surgical risks has high complication rate, so external fixation should be considered as a semiconservative method to reduce operative time and complications.

Patients and methods: Forty elderly high risk patients with intertrochanteric fracture were treated by Ilizarov fixator. All patients had uncontrolled concomitant medical disorders as hypertension, cardiac disease, diabetes mellitus and chronic hepatic or renal failure.

Results: All patients were evaluated clinically \& radiologically from 5 months to 12 months except 2 patients , one died 3 months post operative and the other lost follow up 3.5 month post operative after fixator removal. Excellent and good (satisfactory) results were found in 32 patients and fair and poor (unsatisfactory) results were found in 8 patients. The time of radiological union and fixator removal ranged from 10 weeks to 16 weeks. Pin tract infection occurred in all patients. Varus malalignment occurred in $20 \%$ of patients. Shortening ranged from 0 to $3 \mathrm{~cm}$ in 5 patients.

Conclusion: the study proved that external fixation of intertrochanteric fractures in elderly high risk patients is a reliable, effective and safe treatment option. It offers a minimal operative risk, no blood loss, short hospital stay, early mobilization and low morbidity and mortality.

Key words: Geriatric; Femur; Fracture; Intertrochanteric; Ilizarov fixator

\section{Introduction}

The per trochanteric fractures of the femur have been marked as one of the biggest problems of the geriatric trauma. The patients with this type of fracture occupy at least $30 \%$ of beds in the orthopedic institutions. These fractures are more common in older patients, above 65 years of age, when there is far greater loss of the skeletal mass (osteoporosis) [1-3]. Low energy trauma like simple falls, increased longevity together with osteoporosis and senile muscular insufficiency may explain the increasing number of patient with intertrochanteric fractures, and women are three times more liable to these types of fractures [4]. The goal of treatment remains return of the patients to their preoperative status in the earliest possible time with low morbidity and mortality and union in the appropriate position [4].

Intertrochanteric fracture can be treated conservatively by traction or surgical by many methods either by open reduction and internal fixation with nails or plates (as dynamic hip screw), or by calcar replacement or by external fixator [5]. Elderlies mostly have medical problems like diabetes mellitus, hypertension, stroke and cardiopulmonary problems and are unable to tolerate major surgical procedures requiring long operative time and risk of excessive bleeding, also. They are also not suitable for conservative treatment which carries the risk of prolonged recumbences. So, external fixator is a salvage procedure for high risk geriatric patients. It offers significant advantages in the form of minimal surgical trauma, negligible blood loss, preservation of fracture haematoma, short operative time and minimal anaesthetic complications, allowing early ambulation of the patient, easy day care, shorter hospital stay and removal of the implant as a simple outpatient procedure [6-9].

\section{Patients and Methods}

Forty risky patients with intertrochanteric fracture were operated from august 2015 to June 2017 by Ilizarov fixator. All cases that fulfilled the inclusion criteria had been included in the study. The study include the patients with fractures of non pathological origin, closed or open, in patients with age equal or more than 60 years and unfit for surgery of long time and excessive bleeding due 
to combined chronic hepatic or renal failure, uncontrolled medical disorders as hypertension, diabetes mellitus, cardiac disease and excluded patients with ipsialteral fracture femur. The fractures were classified according to modified Evan's classification $[10,11]$. The study include 24 patients with stable fracture pattern (6 was type I, 18 was type II) and 16 had unstable fracture pattern (8 was type IV, 8 was type V).

\section{Surgical Technique}

Preoperative intravenous broad spectrum antibiotics were given an hour before surgery. Local infiltration anasthesia was used in $75 \%$ of patients. The patient was placed supine on a radiolucent orthopedic traction table under $\mathrm{C}$ arm guidance. The construct used was uniplanar Ilizarov fixator. Closed reduction was achieved by traction, abduction and internal rotation. At an angle of approximately $130^{\circ}$ through the middle of the femoral neck into the head temporary guide wire was inserted percutaneously. A $6 \mathrm{~mm}$ Schanz screw was introduced gradually into the femoral neck from the base of the greater trochanter across the fracture site at an angle of $125^{\circ}-130^{\circ}$ with the femoral shaft above the guide wire in the anteroposterior view and central in the lateral view. The tip of the Schanz was stopped $0.5-1 \mathrm{~cm}$ from the articular surface of the head. A second proximal Schanz was inserted into the femoral neck below the guide wire in the anteroposterior view and central in the lateral view. Two $6 \mathrm{~mm}$ Schanz screws were inserted perpendicular to the proximal femoral diaphysis. All schanz screws were connected by Ilizarov accessories like plates, rancho cubes, male supports, rods, nuts and conical washers. The final position was checked and the frame was tightened (Figures 1a \& b).

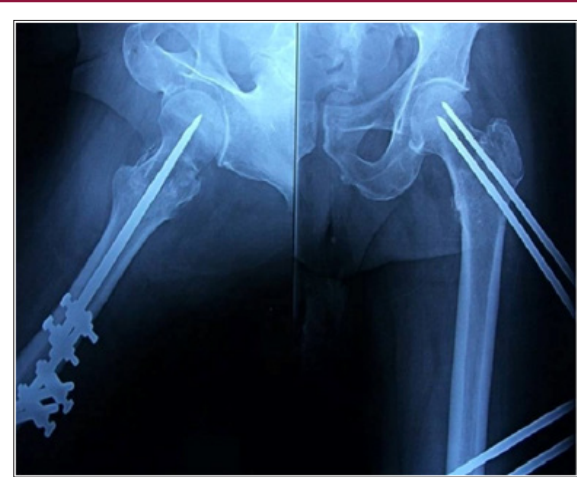

Figure 1a: Radiographs 12 weeks postoperatively showing complete union.

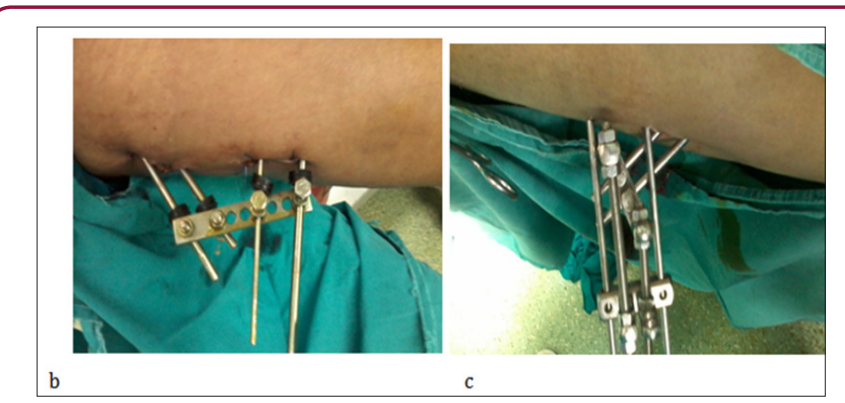

Figure 1b \& c: clinical picture showing the frame after insertion.

\section{Postoperative Care}

Antibiotics were continued for 3 days together with analgesics also anticoagulants were prescribed during the period of nonweight bearing. Immediate radiographs were obtained. The mean period of hospitalization after operation was 4.5 days (range 3-6 days). Patients were asked to review every two weeks in the first month and then every month at the out-patient clinic for clinical and radiological assessment. The reduction was considered to be anatomical if the neck-shaft angle was reproduced and the gap at the fracture site was less than $2 \mathrm{~mm}$. Minor valgus angulation $\left(<10^{\circ}\right)$ and a gap of less than $5 \mathrm{~mm}$ were considered to be acceptable if an anatomical reduction was not possible [12]. The patients were followed up for a mean of 8.5 months, range from 5 months to 12 months except 2 patients, one died 3 months post operative and the other lost follow up 3.5 month post operative after fixator removal. After discharge from hospital patients were followed up every 2 weeks in first month and every month to the end of follow up after union and fixator removal . Active exercises, sitting in bed was allowed early. Partial weight bearing using a walker (a four leg frame) 6-16 weeks postoperative, and this was depending on the general condition of the patient, type of the fracture, stability of reduction, pre fracture walking ability and pain on walking. On completely union, the fixator was removed. The removal was done as a simple procedure at the outpatient clinic.

The functional outcome was evaluated according to Merle d'Aubigne scor 7 ing system $[13,14]$.

\section{Statistical Analysis}

Chi-square $(\chi 2)$ test was used for comparison between satisfactory and unsatisfactory results and P-value to detect statistical significance.

\section{Results}

In this study, the mean follow up period was 8.5 months (range 5-12 months). Excellent and good results were considered satisfactory while unsatisfactory include fair and poor results. Results were satisfactory in 32 patients (80\%) and unsatisfactory in 8 patients $(20 \%)$. Of the studied patients 12 were males (30\%) and 28 were females (70\%). The left side was affected in 20 patients (50\%) and the right side was affected in 20 patients (50\%). The mean age was 67.5 years (range $60-85$ years). There was significant higher incidence of satisfactory results in the age groups (60-70) and $(70-80)$ than unsatisfactory results and a significant higher incidence of unsatisfactory results was observed in the oldest age group (80-85), P-value $<0.01$. So, the younger the age the better the result. Twenty four patients had stable fracture pattern as in (Figure 1a), (6 was type I, 18 was type II) and 16 had unstable fracture pattern as in (Figure 2a), (8 was type IV, 8 was type V). All stable fractures gave significant satisfactory results, than types IV and V which gave only $75 \%$ and $25 \%$ satisfactory results, respectively (Table 1). The mean time lag before operation was 7 days (range 2-11 days) with no significant effect on the results. The mean operative time was 36 minutes (range 30-45 minutes). 
Table 1: Comparison between satisfactory and unsatisfactory results regarding type of fracture.

\begin{tabular}{|c|c|c|c|c|c|c|c|}
\hline \multirow{2}{*}{ Evan's classification } & \multicolumn{2}{|c|}{ Satisfactory (No=32) } & \multicolumn{2}{|c|}{ Unsatisfactory (No=8) } & \multirow{2}{*}{ Total Number } & \multirow{2}{*}{ X2 } & p-value \\
\cline { 2 - 8 } & No & $\mathbf{9}$ & No & 0 & 6 & 10.63 & 0.01 \\
\hline I & 6 & 100 & 0 & 0 & 18 & \\
\hline II & 18 & 100 & 0 & 25 & 8 & \\
\hline IV & 6 & 75 & 2 & 75 & 8 & \\
\hline
\end{tabular}

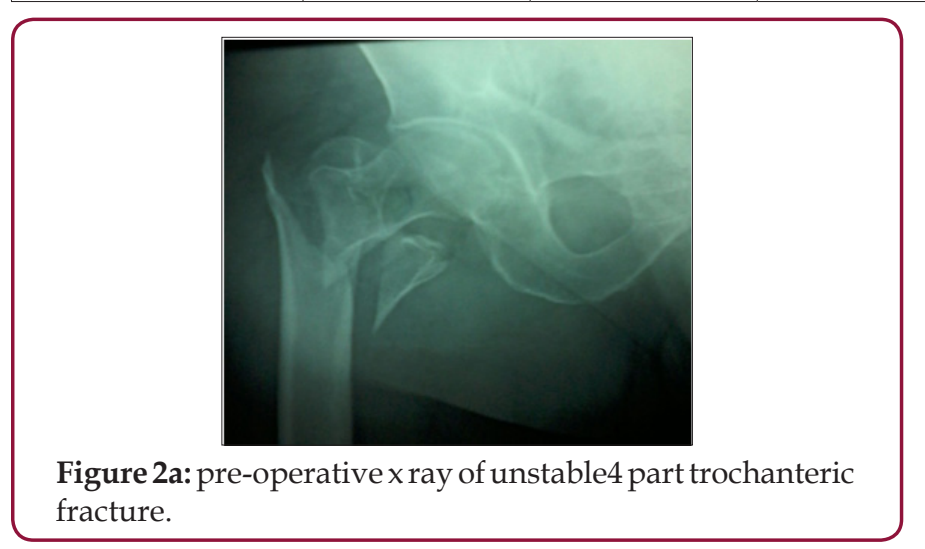

Figure 2a:
fracture.

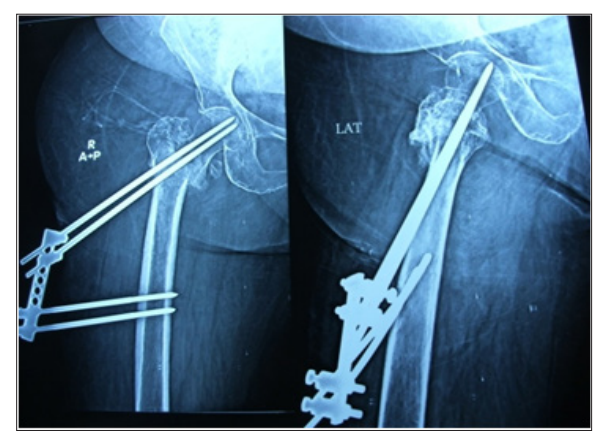

Figure 2b: Intertrochanteric fracture fixed with Ilizarov fixator .

Start of weight bearing ranged from 6 to 16 weeks with a mean of 12 weeks. Although weight bearing before fixator removal gave better satisfactory results $(100 \%)$ than after fixator removal, the difference didn't reach a significant level, P-value $>0.05$. Union occurred in all patients. The time of union and removal of the fixator ranged from 10 weeks to 16 weeks with a mean of $12.4 \pm 1.9$ weeks (Figures $1 \& 2$ ). Pin tract infection developed in all patients to different extent and was treated with antibiotics and daily dressing and was completely cured expect five patients who had type IV pin tract infection, early removal was necessary to control infection. It had insignificant effect on the results. The range of varus malalignment was from 0 to 10 degrees in 28 patients while 12 patients were more than 10 degrees. Also, it had insignificant effect. Shortening ranged between 0 and $3 \mathrm{~cm}$ in 5 patients due to impaction and varus deformity. All cases with shortening more than $2 \mathrm{~cm}$ had unsatisfactory results $(100 \%)$. So, the less the shortening the better the result. Penetration of the pins occurred in four patients. It was easily managed by simply screwing out of the proximal pins for about $2 \mathrm{~cm}$ in the out-patient clinic in one patient, the other patients managed by early removal of the fixator due to the associating severe pin tract infection.

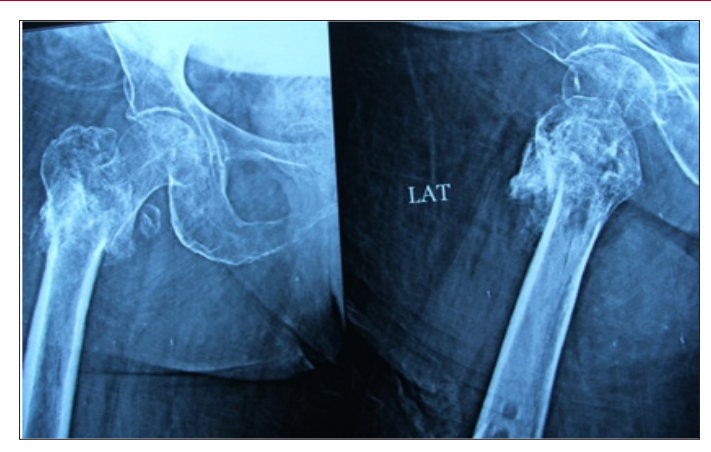

Figure 2c: Intertrochanteric fracture united after removal of Ilizarov fixator.

\section{Discussion}

It was found that satisfactory results in this study was $80 \%$, while that published by Kazakos et al. [7] was $84 \%$ and Vossinakis \& Baradas [15] was $100 \%$ and that published by Dhal et al. [16] , Subasi et al. [4], Mitkovic et al. [2] and Refaat et al. [17] reported $93.5 \%, 88 \%, 83.24 \%$ and $82.2 \%$ satisfactory results respectively. Satisfactory results were $(100 \%)$ in stable fractures while they were $(75 \%)$ and) $25 \%$ ) in types IV and V (unstable fractures) respectively with a statistically significant effect of fracture stability on the results. This could be explained that stable fractures allow earlier union and weight bearing and hence better rehabilitation and satisfactory results, while unstable fractures are more prone to complications such as shortening and varus deformity and hence worse results. The mean operative time was 36 minutes. This coincides with the results of Aly et al. [6], Kazakos et al. [7] stated a mean operative time of 35,37 minutes in their group while Dhal et al. [16] stated a mean operative time of 30 minutes.

No patients in this study required intra or post-operative blood transfusion, also the blood loss was negligible and this was the same as that mentioned by other authors. Gradual weight bearing was delayed to 6-16 weeks after operation (with a mean of 12 weeks) due to osteoporosis to guard against fracture displacement, implant failure, collapse, varus malalignment and penetration of the femoral head. This doesn't coincide with that reported by Refaat et al. [17] in which Partial weight bearing was begun as soon as the patient could in stable fractures and after 6 weeks in unstable ones. Union occurred in a mean period of $12.4 \pm 1$.9 weeks ranging from 10 to 16 weeks. This coincides with the experiences of many authors as Subasi et al. [4] and Catagni et al. [18] who stated that union achieved at 10-18 and 10-12 weeks respectively. Pin-tract infection, it occurred in all patients, they all were minor infections expect five cases who had major infection requiring frame removal. 
Refaat et al. [17] reported that Superficial infection was detected in $(33.9 \%)$ of patients while deep infection was detected in $(19.4 \%)$ of patients.

\section{Conclusion}

Ilizarov fixator in intertrochanteric fracture in geriatric high risk patients has the advantages of minimal surgical trauma, preservation of fracture haematoma, , negligible blood loss short operative time, minimal anaesthetic complications, possibility of application under local anaesthesia, possibility of frame adjustment, short hospital stay and removal of the construct as simple outpatient procedure. Ilizarov fixator has the advantage over other unilateral fixators in its unlimited configurations, secure, tight and rigid stable fixation. The most important advantage is the ability to adjust the angle between the neck shanz pins and the femral shaft pins to restore the normal neck shaft angle. This study proved that the more the fracture stability the better the results.

\section{References}

1. Salunkhe R, Limaye S, Biswas S, Mehta R (2012) Cemented hemiarthroplasty in proximal femoral fractures in elderly with severe osteoporosis: A case series. Medical Journal of Dr PY Patli University 5(1): 36-42.

2. Mitkovic M, Milenković S, Radenković M, Miadenović D, Golubvić Z, et al. (2003) Surgical treatment of the trochanteric fractures by using the external and internal fixation methods. Medicine and Biology 10(2):7983.

3. Milorad M, Milenković S, Bumbasirević M, Lesic A, Golubvić Z, et al. (2002) Surgical treatment of the pertrochanteric fractures by using personal external fixation system and technique. Medicine and Biology. 9(2): 188-191.

4. Subasi M, kesemenli C, Kapukaya A, Necmioglu S (2001) Treatment of intertrochanteric fractures by external fixation. Acta Orthopaedica Belgica 67(5): 468-474.

5. Evans EM, Birmingham (1949) The treatment of trochanteric fracture of the femur. J Bone Joint Surg 31-B(2): 190-203.

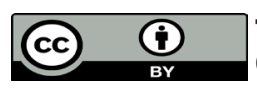

This work is licensed under Creative Commons Attribution 4.0 License

Submission Link: http://biomedres.us/submit-manuscript.php
6. Aly TA, Hafez K, Abo El-nor K, Amin O (2004) Treatment of trochanteric fractures by external fixator in patients with high unacceptable operative risk. Pan Arab J Ortho Trauma 8(2): 157-162.

7. Kazakos K, Dimitrios N, Verettas D, Galanis V, Psillakis I, et al. (2007) External fixation of intertrochanteric fractures in elderly high risk patients. Acta Orthop 73(1): 44-48.

8. Karn NK, Singh GK, Kumar P, Shrestha BP, Singh MB, et al. (2006) Comparison between external fixation and sliding hip screw in the management of trochanteric fracture of the femur in Nepal. J Bone Joint Surg 88(10)B: 1347-1350.

9. Elmoafy H, Abd Elsattar T, Elreweny M (2014) Management of intertrochanteric fracture in elderly high-risk patients using simple external fixation. Menoufia Medical Journal 27(2): 249-254.

10. Jensen J (1980) Classification of trochanteric fracture. Acta orthop scand 51(5): 803-810.

11. Mabesoone F (2015) Classification of Trochanteric Fracture Patterns. The Orthopedic Journal On The Web 1-10.

12. Ahmed AR (2014) An innovative external fixator for the management of trochanteric fractures of the femur. Egyptian Orthopaedic Journal 49(1): 1-5.

13. Merle d'Aubigne, Postel M (1954) Functional results of arthroplasty with acrylic prosthesis J Bone Joint Surgery 35A(3): 451-475.

14. Abdul Ghani FM (2014) External fixation in the treatment of intertrochanteric fractures in elderly patients. Medical Journal of Babylon 11(2):1-3.

15. Vossinakis IC, Badras LS (2001) Management of pertrochanteric fractures in high-risk patients with an external fixation. Springer-Verlag 25(4): 219-222.

16. Dhal A, Varghese M, Bhasin VB (1991) External fixation of intertrochanteric fracture of the femur.J. Bone Joint Surg 73(6): 955-958.

17. Refaat A, Gaber H, Hassan A (2009) External fixation of trochanteric fractures in high risk patients. The Egyptian Orthopaedic Journal 44: 342-355.

18. Catagni M, Sdeek M, Guerresche F, Tsibidakis H, Lovisetti L (2012) Management of proximal femoral fractures using the Ilizarov principles. Acta Orthop. Belg 78(5): 588-591.

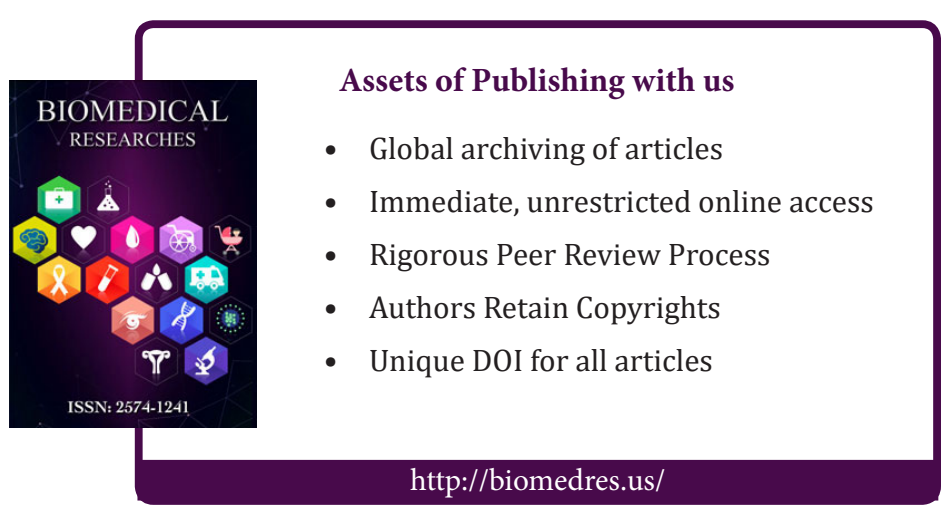

